\title{
SIGNS AND SYMPTOMS OF MERCURY-EXPOSED GOLD MINERS
}

\section{STEPHAN BOSE-0'REILLY ${ }^{1,2}$, LUDOVIC BERNAUDAT ${ }^{3}$, UWE SIEBERT $^{2,4,5}$, GABRIELE ROIDER, DENNIS NOWAK ${ }^{1}$, and GUSTAV DRASCH ${ }^{6}$}

${ }^{1}$ University Hospital Munich, Munich, Germany

Institute and Outpatient Clinic for Occupational, Social and Environmental Medicine, WHO Collaborating Centre for Occupational Health

${ }^{2}$ The Health and Life Sciences University (UMIT), Hall in Tirol, Austria

Institute of Public Health, Medical Decision Making and Health Technology Assessment,

Department of Public Health

Health Services Research and Health Technology Assessment

${ }^{3}$ United Nations Industrial Development Organization (UNIDO), Vienna, Austria

Vienna International Centre

${ }^{4}$ Harvard Medical School, Boston, USA

Massachusetts General Hospital, Institute for Technology Assessment and Department of Radiology

${ }^{5}$ Harvard T.H. Chan School of Public Health, Boston, USA

Center for Health Decision Science, Department of Health Policy and Management

${ }^{6}$ University of Munich, Munich, Germany

Department of Forensic Toxicology, Institute of Forensic Medicine

\footnotetext{
Funding: data from differently funded projects were the basis for this paper. The projects in Indonesia, Philippines, Tanzania and Zimbabwe (2004) were executed by United Nations Industrial Development Organization (UNIDO) as part of the Global Mercury Project (GMP) with means from the Global Environment Facility (GEF). The project in Zimbabwe in 2006 was funded with a personal grant from Beate Lettmeier and in kind contributions from Ludwig-Maximilians University (LMU), Munich, Germany, and in kind contribution from University for Health Sciences, Medical Informatics and Technology (UMIT), Hall in Tirol, Austria. The project in Mongolia was funded by World Health Organization (WHO) together with the Ministry of Health of Mongolia and in kind contribution from National Institute of Minamata Disease, Minamata, Kumamoto, Japan, and the Health and Safety Laboratory, Harpur Hill, Buxton, United Kingdom. The analysis for this paper was not funded at all, and is completely an in-kind contribution of all authors.

Received: June 23, 2015. Accepted: February 16, 2016.

Corresponding author: S. Bose-O'Reilly, University Hospital Munich, Institute and Outpatient Clinic for Occupational, Social and Environmental Medicine, WHO Collaborating Centre for Occupational Health, Ziemssenstr. 1, D-80336 Munich, Germany (e-mail: Stephan.Boeseoreilly@med.uni-muenchen.de).
} 


\begin{abstract}
Objectives: Gold miners use mercury to extract gold from ore adding liquid mercury to the milled gold-containing ore. This results in a mercury-gold compound, called amalgam. Miners smelt this amalgam to obtain gold, vaporizing it and finally inhaling the toxic mercury fumes. The objective was to merge and analyze data from different projects, to identify typical signs and symptoms of chronic inorganic mercury exposure. Material and Methods: Miners and community members from various artisanal small-scale gold mining areas had been examined (Philippines, Mongolia, Tanzania, Zimbabwe, Indonesia). Data of several health assessments were pooled. Urine, blood and hair samples were analyzed for mercury $(\mathrm{N}=1252)$. Questionnaires, standardized medical examinations and neuropsychological tests were used. Participants were grouped into: Controls $(\mathrm{N}=209)$, living in an exposed area $(\mathrm{N}=408)$, working with mercury as panners $(\mathrm{N}=181)$, working with mercury as amalgam burners $(\mathrm{N}=454)$. Chi ${ }^{2}$ test, linear trend test, Mann-Whitney test, Kruskal-Wallis test, correlation coefficient, Spearman's rho, and analysis of variance tests were used. An algorithm was used to define participants with chronic mercury intoxication. Results: Mean mercury concentrations in all exposed subgroups were elevated and above threshold limits, with amalgam burners showing highest levels. Typical symptoms of chronic metallic mercury intoxication were tremor, ataxia, coordination problems, excessive salivation and metallic taste. Participants from the exposed groups showed poorer results in different neuropsychological tests in comparison to the control group. Fifty-four percent of the high-exposed group (amalgam burners) were diagnosed as being mercury-intoxicated, compared to $0 \%$ within the control group $\left(\mathrm{Chi}^{2} \mathrm{p}<0.001\right)$. Conclusions: Chronic mercury intoxication, with tremor, ataxia and other neurological symptoms together with a raised body burden of mercury was clinically diagnosed in exposed people in artisanal small-scale mining areas. The mercury exposure needs to be urgently reduced. Health care systems need to be prepared for this emerging problem of chronic mercury intoxication among exposed people. Int J Occup Med Environ Health 2017;30(2):249-269
\end{abstract}

Key words:

Mercury, Chronic mercury intoxication, Clinical symptoms, Neurological symptoms, Artisanal small-scale gold mining, Elemental mercury

\section{INTRODUCTION}

Artisanal and small-scale gold mining (ASGM) often relies on mercury $(\mathrm{Hg})$ to extract gold. Miners obtain the goldcontaining ores either from underground or from open pit deposits. In order to free the gold particles, it is sometimes necessary to grind the ore mechanically to a fine powder using, e.g., ball mills. The powder is further processed, adding liquid mercury, with or without pre-concentration. Miners are panning this mixture of fine powder, liquid mercury and water, during this so-called "amalgamation," the fine gold particles bind to mercury, resulting in a mercury-gold compound, called "amalgam." To obtain the gold from the amalgam, it is heated until the mercury evaporates, and after this smelting a piece of raw gold sponge remains. This last step is performed by the so called "amalgam burners" or smelters. At both stages (amalgamation and smelting) miners are exposed to mercury, in the case of:

- amalgamation (or panning) - liquid elemental mercury via skin contact and via inhaling evaporating mercury,

- smelting-elemental mercury vaporization via inhalation,

- storing mercury at home - elemental mercury evaporation via inhalation.
The main exposure of these miners is therefore to elemental mercury. Mercury shows acute and chronic toxicity which may result in severe neurological damage affecting especially the cerebellum [1,2]. The described practice of ASGM is very common; it is estimated that up to 1015 million miners work in ASGM areas [3-5]. The chronic exposure to elemental mercury vapor causes health problems among the miners and the people in the mining communities [6-33]. Most of these publications focused on mercury concentration in human samples, only few studies included physical examinations of miners and revealed relevant symptoms [26,31-33]. In our own ASGM studies we had examined a large numbers of miners clinically (Table 1) [17-20,34-37]. The focus was on subjective and objective symptoms of mercury intoxication among miners (smelters and panners) and people living in mining areas compared to a non-exposed control group living outside mining areas.

The intention for this publication was to merge and analyze the data from the different projects, to identify the most typical signs and symptoms of chronic exposure to inorganic mercury. 


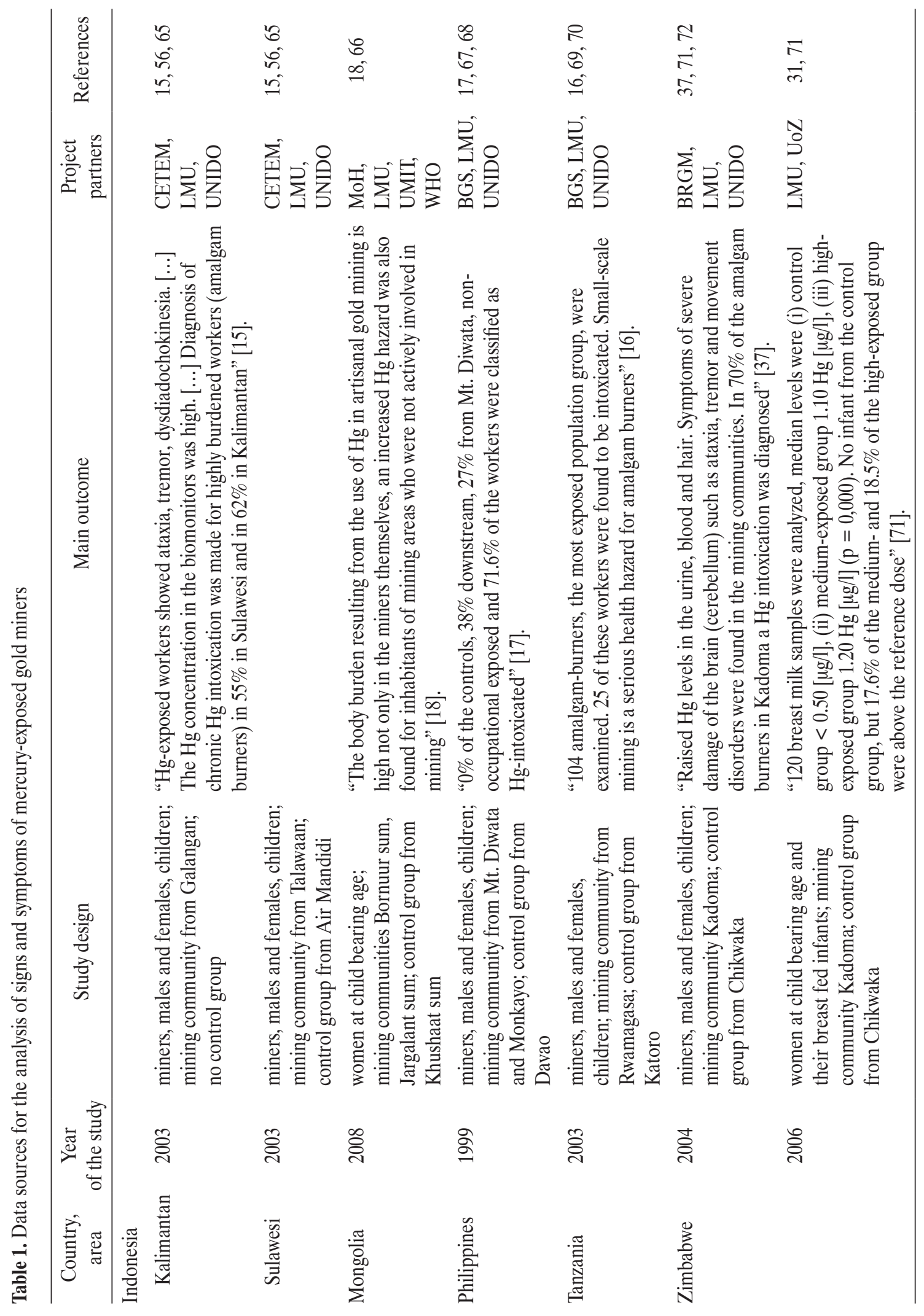

플 믈

를

본

记

晑 1

5 氙

○菏

会善

窟造

동

현

$\sum_{i}$

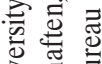

党

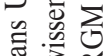

产

気

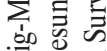

ड़

当进照

㻤

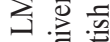

感官

응 울 1

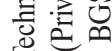

氙窎

竞

호웜

氙志

Uै

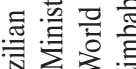

就其 ต․ㅠ 1

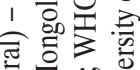

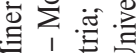

却

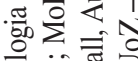

응 言

兽窟

ช

잉ㅎㅁ응

过泀芯

$\sum$ ․․․․

i 응

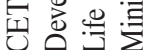




\section{MATERIAL AND METHODS}

This study shows the analysis of merged data from several cross-sectional studies.

\section{Data sources}

Data from former projects were used for this analysis (Table 1). A data bank including all our project data was created and used for this analysis [16].

Data from different projects were pooled: from the Global Mercury Project (GMP) data from the Philippines, Indonesia, Zimbabwe and Tanzania; from World Health Organization (WHO) projects data from Mongolia and from a university project Ludwig-Maximilians University Munich, Germany (LMU) data from Zimbabwe in 2006. For this analysis we selected data from adult miners (18-60 years of age).

The results for children had already been published [38]. Thirty-three participants with known severe neurological diseases such as a stroke or Parkinson's disease, and participants obviously drunk during examination were excluded from this analysis. Besides, only participants with reliable exposure history were included, while former miners and miners who had moved to a control area were left out of this analysis. For the project in Kalimantan, Indonesia, we could not use the data of the control group. The laboratory results showed that this group was in fact also an exposed group of miners. In total, 1252 participants were available for further analysis.

The data was stratified according to the different level of exposure:

1. Non-exposed group - control groups, outside of ASGM areas, with no specific contact to mercury $(\mathrm{N}=209)$. Control groups were selected by the national project manager, trying to match to comparable social and economic backgrounds to exposed groups.

2. Low-exposed group - living in exposed areas, but not engaged in mining activities related to mercury $(\mathrm{N}=408)$.

3. Medium-exposed group - working with mercury as panners $(\mathrm{N}=181)$.
4. High-exposed group - working with mercury as amalgam burners $(\mathrm{N}=454)$.

All participants were volunteers. The national project manager together with the respective local health experts selected the participants, according to the inclusion criteria of the specific project. The criteria were: age group, gender and exposure status - the aim was to have sufficient participants within each subgroup. According to these criteria, local study nurses went to their villages and recruited volunteers that fulfilled these criteria. In our opinion, this was the best feasible way in ASGM areas to select participants.

It was not possible in all the field projects to have exactly the same study protocol. For Indonesia, Tanzania and Zimbabwe 2004 the data set was the most complete, including, e.g., speciation of the hair samples. Fewer data parameters were available mainly for Mongolia and Zimbabwe 2006.

For each single project, the involved international institutions (United Nations Industrial Development Organization - UNIDO, United Nations Development Programme - UNDP, WHO) had provided the approval of the relevant national committees to perform the health assessments. Written informed consent in the appropriate regional language was achieved from all volunteering participants. All assessments were carried out respecting the Recommendation for Conduct of Clinical Research from World Health Organization Declaration of Helsinki. The health examinations were performed in close cooperation with UNIDO (United Nations Industrial Development Organization), the United Nations Development Programme (UNDP), WHO, as well as the regional health authorities and national ministries of health. Extensive legal, formal, and ethical issues were considered and all conditions were agreed upon between the governments and WHO/UNIDO. These conditions, approved by the governments, complied with all relevant national, state, and local regulations. 


\section{Health assessment}

An extensive questionnaire, translated into the regional language was applied by local nurses to get information on exposure data, possible confounders such as fish intake or alcohol ingestion, health data including typical symptoms of mercury toxicity such as memory problems, sleeping disturbances, headache, metallic taste or excessive salivation. The participants were clinically, mainly neurologically examined by the same examiner (S.B.), who was blinded for mercury levels of participants. Ataxia, tremor, coordination problems, abnormal reflexes and grey to bluish discoloration of the oral cavity, number of dental amalgam fillings were the main items of the examination, all related to chronic mercury exposure. The signs and symptoms were scored and, if appropriate, Masur's Scales and Scores in Neurology were used [39].

To assess the physical and mental fatigue, a special score was used [40]. The physical score, ranging 0-16, takes into account personal complaints, e.g., need to rest more, getting tired easily, feeling sleepy, lack of energy, less strength in muscles, feeling weak. The mental score, ranging $0-10$, consists of problems to concentrate, thinking clearly and problems with memory. Several neuropsychological and neuromotor tests were performed to assess memory, tremor, ataxia and coordination. The following neuropsychological and neuromotor tests were carried out $[39,41,42]$ :

- digit span test to test the short-term memory (part of Wechsler Memory Scale) - the more numbers in a row a participant can recall without a mistake the better,

- matchbox test to test for coordination, intention tremor and concentration - 20 matches are outside an empty matchbox $15 \mathrm{~cm}$ away to both sides and the faster a participant can put the matches back in the box the better,

- Frostig score (subtest Ia 1-9) to test for tremor and visual-motoric capacities - drawing a line with a pencil between 2 given lines, the lines should not be touched or crossed,
- pencil tapping test to test for intention tremor and coordination - tapping with a pencil within $10 \mathrm{~s}$ dots on a piece of paper, the more dots the better.

\section{Laboratory analysis of urine, blood and hair}

Urine, blood and hair samples were collected from the participants. Hair samples were cut from up to $3 \mathrm{~cm}$ from the scalp. Urine was acidified to avoid degradation. Blood was sampled in ethylenediaminetetraacetic acid (EDTA)-coated vials. Blood and urine were stored and transported at $4^{\circ} \mathrm{C}$ until the samples were analyzed. The analysis of the samples was in general performed in the Institute of Forensic Medicine (LMU): Blood, urine and hair were analyzed by G.R. and her team from LMU with a Cold-Vapor Atomic-Absorption Spectrometer (Perkin-Elmer 1100 B spectrometer and Lumex mercury ColdVapor Atomic-Absorption Spectrometer). To correct for urinary excretion, urinary mercury levels were adjusted for creatinine [43]. Hair samples were not washed, but pretreated and digested.

The urine and hair analysis for the controls from Mongolia was performed by the National Institute for Minamata Disease (Minamata, Kumamoto, Japan) using a ColdVapor Atomic-Absorption Spectrometer (CV-AAS) [20]. The blood analysis of the controls in Mongolia was performed by the Health and Safety Laboratory (Harpur Hill, Buxton, United Kingdom) using an Inductively-CoupledPlasma Mass Spectrometer (ICP-MS).

Adequate strict external and internal quality control was guaranteed. Quality controls with reference samples were continuously achieved to guarantee the precision of the results. An extensive article on the results of our human biomonitoring data has been already published, and this article contains more detailed information on the laboratory methods [16] as well as our former country-related articles [17-20,44].

The limit of detection (LOD) for urine analysis was $0.1 \mu \mathrm{g} / \mathrm{l}$ for the controls from Mongolia, $0.2 \mu \mathrm{g} / \mathrm{l}$ for 
Indonesia, Tanzania, Zimbabwe plus the exposed groups from Mongolia, $0.5 \mu \mathrm{g} / \mathrm{l}$ for the Philippines. The LOD for blood analysis was $0.2 \mu \mathrm{g} / \mathrm{l}$ for all countries, except for the Philippines with $0.50 \mu \mathrm{g} / \mathrm{l}$. The LOD for hair analysis was $0.01 \mu \mathrm{g} / \mathrm{g}$ for the controls from Mongolia plus the Philippines, and $0.02 \mu \mathrm{g} / \mathrm{g}$ for Zimbabwe, Tanzania and Indonesia. For inorganic hair the LOD was $0.05 \mu \mathrm{g} / \mathrm{g}$. For results below the limit of detection (LOD), the value was set to $1 / 2$ the detection limit for the statistical analysis.

Mercury can damage the kidney function, and proteinuria is one of the consequences. With commercial kit $\left(\right.$ Bayer $\left.^{\circledR}\right)$ we tested for proteinuria.

\section{Statistical methods}

The analytic strategy was to describe signs, symptoms and mercury levels stratified by exposure group. Many test results were primarily scored and later reduced to a yes/no decision without loss of relevant information (score 1/0). The neuropsychological tests (memory, matchbox, Frostig, pencil tapping) were divided into 3 categories: best performing 25\%, performing between $25 \%$ and $75 \%$ and worst performing $25 \%$ of participants (score 0/1/2).

The mercury concentrations in urine, blood and hair had a distribution with a tail to the right, and were therefore log-transformed. Descriptive measures (mean, median, range, standard deviation (SD), quartiles, 95\% confidence limits, boxplots) were used. Metric human specimen data and neuropsychological data were analyzed using the Mann-Whitney test to search for differences between the groups and the Kruskal Wallis test to identify differences over all groups. Pearson's Chi test was used to compare non-metric clinical data to see if there was any difference between the subgroups. To identify possible trends between the 4 groups (control, low-exposed, medium-exposed, high-exposed) the linear trend test was applied. To compare normal-distributed metric data between subgroups, analysis of variance (ANOVA) was used. Univariate correlation of mercury levels with each other (nonparametric and parametric) and other parameters was applied (correlation coefficient and pvalues by non-parametric Spearman's rho). Mercury levels were compared with recommended threshold values. The significance level has been set at $\alpha=0.05$. The IBM SPSS version 20 software was used for the analysis.

Chronic alcohol ingestion causes severe neurological symptoms, such as tremor, depending on the dose and duration. Men are more likely to consume alcohol. A separate analysis for female/male participants of the 4 subgroups was performed to detect differences between the men and women [45]. Dental amalgam fillings contain elemental mercury, and might contribute to the body burden of mercury. The number of dental amalgam fillings was counted in the mouth of all participants. The objective of this study was to focus on the clinical signs and symptoms. The study was restricted to a univariate analysis of the data.

Fish contains methyl-mercury and contributes to the body burden of mercury. A correlation test was performed to test for a correlation between fish consumption and mercury levels in human specimens or medical score sum.

\section{Threshold values and diagnostic algorithm}

A medical score sum was formed, using anamnestic data, clinical data, neuropsychological parameters and the result of analyzing protein content in urine (Table 2). This medical score is based on the results from the first project in an ASGM area in the Philippines [19]. A high medical score sum is associated with the typical severe signs and symptoms of chronic mercury intoxication. The score ranged $0-21$, a medical score sum $0-4$ was considered as low, 5-9 medium and 10-21 high.

To stratify the health risk, we used the so-called human biomonitoring (HBM) values published by the German 
Table 2. Medical score sum parameters in the study of signs and symptoms of mercury-exposed gold miners

\begin{tabular}{lc}
\hline \multicolumn{1}{c}{ Test } & $\begin{array}{c}\text { Score* } \\
{[\mathrm{pts}]}\end{array}$ \\
\hline Anamnestic data & \\
metallic taste & $0 / 1$ \\
excessive salivation & $0 / 1$ \\
tremor at work & $0 / 1$ \\
sleeping problems at night & $0 / 1$ \\
health problems worsened since Hg exposed & $0 / 1$ \\
Clinical data & \\
grey to bluish discoloration of the oral cavity & $0 / 1$ \\
ataxia of gait & $0 / 1$ \\
finger to nose tremor & $0 / 1$ \\
dysdiadochokinesia & $0 / 1$ \\
heel to knee ataxia & $0 / 1$ \\
heel to knee tremor & $0 / 1$ \\
mento-labial reflex & $0 / 1$ \\
proteinuria & $0 / 1$ \\
Neuropsychological tests & \\
memory test & $0 / 1 / 2$ \\
matchbox test & $0 / 1 / 2$ \\
Frostig test & $0 / 1 / 2$ \\
pencil tapping test & $0 / 1 / 2$ \\
Maximum & 21 \\
\hline
\end{tabular}

* Medical score sum parameters: anamnestic and clinical data: 0 - no symptom, 1 - pathological symptom; neuropsychological and neurometric tests: 0 - best quartile, 1 -2nd and 3rd quartile, 2 - worst quartile [19].
Human Biomonitoring Commission [46,47]. The selection of threshold values applied for this study was discussed in our former papers $[16,19,48]$. The HBM values were recently updated, including the reference values [49]. Values < HBM I are considered as safe levels, between HBM I and II - as alert levels, and above HBM II - as action levels. Another threshold value is the biological tolerance value (BAT) from the German Commission for the Investigation of Health Hazards of Chemical Compounds in the Work Area. Workers with specimen levels above the BAT are not allowed to work any longer. For total mercury in hair, comparable limits were set [19].

The following categories were established (Table 3):

- below HBM I (if all specimens results were below HBM I),

- from HBM I to HBM II (if a least 1 specimen result was above HBM I but all below HBM II),

- from HBM II to BAT (if at least 1 specimen result was above HBM II but all below BAT) and, if available,

- above BAT (if any specimen result was above BAT).

To define a chronic mercury intoxication, an algorithm including the medical score and mercury threshold values in urine, blood and hair was developed using the results from our first study in the Philippines [19] (Table 4).

Table 3. Toxicologically established threshold limits for mercury in blood, urine and hair

\begin{tabular}{|c|c|c|c|c|}
\hline \multirow{3}{*}{ Threshold/reference value } & \multicolumn{4}{|c|}{ Mercury $(\mathrm{Hg})$ threshold limit } \\
\hline & \multicolumn{2}{|c|}{ urine } & \multirow{2}{*}{$\begin{array}{l}\text { blood } \\
{[\mu \mathrm{g} / \mathrm{l}]}\end{array}$} & \multirow{2}{*}{$\begin{array}{c}\text { hair } \\
{[\mu \mathrm{g} / \mathrm{g}]}\end{array}$} \\
\hline & $\mu \mathrm{g} / \mathrm{l}$ & $\mu \mathrm{g} / \mathrm{g}$ creatinine & & \\
\hline Reference value for adults & 1.0 & - & 2.0 & - \\
\hline \multicolumn{5}{|l|}{ HBM } \\
\hline < HBM I (low level) & $\leq 7$ & $\leq 5$ & $\leq 5$ & $\leq 1^{*}$ \\
\hline HBM I - HMB II (alert level) & $>7$ to $\leq 25$ & $>5$ to $\leq 20$ & $>5$ to $\leq 15$ & $>1$ to $\leq 5^{*}$ \\
\hline > HBM II (high level) & $>25$ & $>20$ & $>15$ & $>5^{*}$ \\
\hline BAT & $>30$ & $>25$ & $>25$ (inorganic $\mathrm{Hg}$ ) & - \\
\hline
\end{tabular}

* For hair there is no direct HBM level. The given values are derived from a stable ration between blood and hair [19]. HBM - Human Biomonitoring value; BAT - Biological Tolerance Values. 
Table 4. Algorithm for the diagnosis of chronic mercury intoxication

\begin{tabular}{lccc}
\hline \multirow{2}{*}{ Mercury presence } & \multicolumn{3}{c}{$\begin{array}{c}\text { Medical score sum } \\
{[\mathrm{pts}]}\end{array}$} \\
\cline { 2 - 4 } & $0-4$ & $5-9$ & $10-21$ \\
\hline $\begin{array}{l}\text { In all specimens } \\
<\text { HBM I }\end{array}$ & - & - & - \\
At least in 1 specimen & & & + \\
$>$ HBM I & - & - & + \\
$>$ HBM II & - & + & + \\
$>$ BAT & + & + & \\
\hline
\end{tabular}

Abbreviations as in Table 3.

"-" - no intoxication, "+" - intoxication.

\section{RESULTS}

In most subgroups there were more female than male participants. Only the subgroup of medium-exposed participants was nearly equally distributed (Table 5).
This needed to be considered in the further analysis, as it is likely that men had a higher exposure to mercury compared to women. The age of the 4 subgroups was comparable (30-32 years).

Table 5. Basic information about respondents in the study of signs and symptoms of mercury-exposed gold miners

\begin{tabular}{|c|c|c|c|c|}
\hline \multirow{2}{*}{ Respondents characteristic } & \multicolumn{4}{|c|}{$\begin{array}{l}\text { Study group }{ }^{1} \\
(\mathrm{~N}=1252)\end{array}$} \\
\hline & $\begin{array}{c}\text { non-exposed } \\
(\mathrm{N}=209)\end{array}$ & $\begin{array}{c}\text { low-exposed } \\
(\mathrm{N}=408)\end{array}$ & $\begin{array}{l}\text { medium-exposed } \\
\quad(\mathrm{N}=181)\end{array}$ & $\begin{array}{c}\text { high-exposed } \\
(\mathrm{N}=454)\end{array}$ \\
\hline Age [years] (Me) & 30 & 31 & 32 & 32 \\
\hline Female/male ratio & $142 / 67$ & $330 / 78$ & $92 / 89$ & $136 / 318$ \\
\hline males $[\%]$ & 32.1 & 19.1 & 49.2 & 70.0 \\
\hline \multicolumn{5}{|l|}{ Region and year of the study [n] } \\
\hline \multicolumn{5}{|l|}{ Indonesia } \\
\hline Kalimantan, 2003 (N = 168) & 0 & 67 & 31 & 70 \\
\hline Sulawesi, $2003(\mathrm{~N}=122)$ & 21 & 17 & 22 & 62 \\
\hline Mongolia, 2008 (N = 196) & 41 & 92 & 13 & 50 \\
\hline Philippines, 1999 ( $\mathrm{N}=232)$ & 37 & 106 & 50 & 39 \\
\hline Tanzania, $2003(\mathrm{~N}=218)$ & 31 & 50 & 34 & 103 \\
\hline Zimbabwe, 2004 (N = 193) & 36 & 22 & 18 & 117 \\
\hline Zimbabwe, 2006 (N = 123) & 43 & 54 & 13 & 13 \\
\hline
\end{tabular}

${ }^{1}$ Non-exposed group - control groups, outside of artisanal and small-scale gold mining (ASGM) areas, with no specific contact to mercury, selected by the national project manager, trying to match to comparable social and economic backgrounds to exposed groups; low-exposed group - living in exposed areas, but not engaged in mining activities related to mercury; medium-exposed group - working with mercury as panners; high-exposed group - working with mercury as amalgam burners. 


\section{Health assessment results}

Table 6 shows the analysis of the anamnestic data. The participants with higher exposure clearly reported considerably more symptoms compared to the control group. The symptoms included metallic taste, excessive salivation, sleep disturbances, loss of hair, feeling nervous or sad, palpitations, headache, nausea and feeling of numbness. A clear ascending trend between the subgroups could only be shown for some symptoms. The mean values of the special score to assess physical fatigue were 0.49 for the control group, 1.92 for the low-exposed group, 1.79 for the medium-exposed group and 1.69 for the high-exposed group; for the mental fatigue score the mean values were $0.39,0.84,0.73$ and 0.97 , respectively. These scores indicated that the participants from the control group felt physically and mentally better.

Table 6. Clinical data, signs and symptoms of mercury-exposed gold miners

\begin{tabular}{|c|c|c|c|c|c|c|}
\hline \multirow[t]{2}{*}{ Sign or symptom } & \multicolumn{4}{|c|}{$\begin{array}{c}\text { Study group } \\
{[\%]}\end{array}$} & \multirow[t]{2}{*}{$\mathrm{p} \mathrm{Chi}^{2}$} & \multirow{2}{*}{$\mathrm{p}_{\text {trend }}$} \\
\hline & non-exposed & low-exposed & medium-ex & h-exposed & & \\
\hline \multicolumn{7}{|l|}{ Anamnestic data } \\
\hline metallic taste & 2.4 & 15.0 & 19.9 & 17.8 & $<0.000$ & $<0.000$ \\
\hline excessive salivation & 6.8 & 12.5 & 22.7 & 23.3 & $<0.000$ & $<0.000$ \\
\hline sleep disturbances & 12.4 & 28.7 & 38.1 & 25.8 & $<0.000$ & 0.009 \\
\hline loss of hair & 8.1 & 34.1 & 29.3 & 18.3 & $<0.000$ & 0.736 \\
\hline feel nervous & 3.1 & 11.5 & 11.0 & 12.9 & 0.021 & 0.010 \\
\hline feel sad & 6.2 & 19.1 & 16.1 & 19.9 & 0.004 & 0.006 \\
\hline palpitations & 10.1 & 14.3 & 21.2 & 21.7 & 0.009 & 0.001 \\
\hline headache & 13.2 & 37.1 & 41.0 & 27.7 & $<0.000$ & 0.192 \\
\hline nausea & 4.7 & 18.6 & 19.5 & 14.8 & 0.002 & 0.123 \\
\hline feel numbness & 7.0 & 26.7 & 32.2 & 27.1 & $<0.000$ & $<0.000$ \\
\hline \multicolumn{7}{|l|}{ Clinical data } \\
\hline grey to bluish discoloration of oral cavity & 6.7 & 17.2 & 25.4 & 23.8 & $<0.000$ & $<0.000$ \\
\hline finger to nose tremor & 5.3 & 18.2 & 15.6 & 12.4 & $<0.000$ & 0.465 \\
\hline heel to shin intentional tremor & 4.3 & 26.3 & 20.8 & 9.9 & $<0.000$ & 0.147 \\
\hline ataxia of gait (walking) & 11.5 & 30.7 & 21.0 & 35.9 & $<0.000$ & $<0.000$ \\
\hline heel to shin ataxia & 8.5 & 36.4 & 37.5 & 31.5 & $<0.000$ & 0.001 \\
\hline dysdiadochokinesia & 17.3 & 37.9 & 41.1 & 35.0 & $<0.000$ & 0.002 \\
\hline abnormal quadriceps reflex (knee) & 12.4 & 18.6 & 23.7 & 22.5 & 0.030 & 0.007 \\
\hline abnormal mento-labial reflex & 26.9 & 20.1 & 16.1 & 27.4 & 0.033 & 0.361 \\
\hline bradykinesia & 3.4 & 9.0 & 19.0 & 16.5 & 0.001 & $<0.000$ \\
\hline hypomimia & 2.4 & 6.2 & 12.7 & 16.2 & $<0.000$ & $<0.000$ \\
\hline proteinuria & 10.8 & 12.6 & 15.6 & 11.1 & 0.471 & 0.932 \\
\hline
\end{tabular}

${ }^{1}$ Study groups as in Table 5.

$\mathrm{Chi}^{2}$ test $\mathrm{p}<0.05$ is significant. 
The differences between the exposed groups were smaller and without a clear trend.

The analysis of the clinical data (Table 6) showed the prevalence of the typical symptoms of chronic mercury exposure, such as grey to bluish discoloration of the oral cavity, tremor (finger to nose and heel to shin intentional tremor), ataxia (gait and heel to shin ataxia), as well as coordination problems (dysdiadochokinesia). Some reflexes were abnormal, such as the knee jerk and the mento-labial reflex. It was also possible to observe bradykinesia and hypomimia, the symptoms reflecting the fatigue of the exposed participants. Once again there was usually a strong difference between the control group and the exposed groups, whereas the trends from non- to high-exposed groups were not so obvious. Proteinuria did not show any trend. The neuropsychological data was analyzed (Table 7) using the Kruskal Wallis test, which identified significant differences between all subgroups for the memory test, the matchbox test and the pencil tapping test, but not for the Frostig test. With the help of the Mann-Whitney test it was possible to show that mainly the high-exposed group had statistically poorer results for the memory test,

Table 7. Neuropsychological data of mercury-exposed gold miners

\begin{tabular}{|c|c|c|c|c|}
\hline \multirow{2}{*}{ Test } & \multicolumn{4}{|c|}{ Study group ${ }^{1}$} \\
\hline & non-exposed & low-exposed & medium-exposed & high-exposed \\
\hline \multicolumn{5}{|l|}{ Memory test } \\
\hline respondents [n] & 125 & 262 & 155 & 389 \\
\hline \multicolumn{5}{|l|}{ score } \\
\hline $\mathrm{M} \pm \mathrm{SD}$ & $2.0 \pm 1.4$ & $2.3 \pm 1.2$ & $2.3 \pm 1.2$ & $2.5 \pm 1.1$ \\
\hline $\mathrm{Me}^{\# \# \#}$ & 2 & $2^{*}$ & 2 (n.s.) & $3^{* * *}$ \\
\hline \multicolumn{5}{|l|}{ Matchbox test } \\
\hline respondents [n] & 199 & 385 & 176 & 450 \\
\hline \multicolumn{5}{|l|}{ score } \\
\hline $\mathrm{M} \pm \mathrm{SD}$ & $19.4 \pm 4.6$ & $19.9 \pm 4.9$ & $20.7 \pm 5.1$ & $21.3 \pm 5.1$ \\
\hline $\mathrm{Me}^{\# \# \#}$ & 19 & 19 (n.s.) & $20^{*}$ & $21^{* * *}$ \\
\hline \multicolumn{5}{|l|}{ Pencil tapping test } \\
\hline respondents [n] & 198 & 385 & 177 & 447 \\
\hline \multicolumn{5}{|l|}{ score } \\
\hline $\mathrm{M} \pm \mathrm{SD}$ & $57.4 \pm 11.3$ & $56.0 \pm 9.8$ & $54.7 \pm 10.9$ & $53.1 \pm 11.6$ \\
\hline$M e^{\# \# \#}$ & 59 & 57 (n.s.) & $57^{*}$ & $54^{* * *}$ \\
\hline \multicolumn{5}{|l|}{ Frostig test } \\
\hline respondents [n] & 88 & 156 & 105 & 350 \\
\hline \multicolumn{5}{|l|}{ score } \\
\hline $\mathrm{M} \pm \mathrm{SD}$ & $10.2 \pm 1.8$ & $9.8 \pm 2.5$ & $10.1 \pm 2.4$ & $10.4 \pm 2.2$ \\
\hline $\operatorname{Me}($ n.s.) & 10.5 & 10.0 (n.s.) & 10.0 (n.s.) & 11.0 (n.s.) \\
\hline
\end{tabular}

M - mean; SD - standard deviation; Me - median; n.s. - not statistically significant.

${ }^{1}$ Study groups as in Table 5.

Mann-Whitney test (each exposed group vs. control group): ${ }^{*} \mathrm{p}<0.05 ;{ }^{* * *} \mathrm{p}<0.001$.

Kruskal Wallis test (difference between any group): ${ }^{\# \#} \mathrm{p}<0.001$. 
the matchbox test and the pencil tapping test, but not for the Frostig test. This analysis indicated that the exposure to mercury impaired short term memory and coordinative functions. The Frostig test seemed inadequate to detect effects related to mercury exposure.

\section{Mercury analysis in urine, blood and hair}

The mercury levels in urine, blood and hair were significantly different in the 4 exposure groups (Table 8). The participants in the different control groups had low mercury levels in all specimens, in general below HBM I levels. The participants in the low-exposed groups had increased mercury levels in all specimens, especially in urine. The participants in the medium- and high-exposed groups had the highest levels. Urine mercury levels in the highexposed groups were in some cases even extremely high. Blood levels showed the same trend that depended on the exposure group, but were not as high as the urinary levels. Hair showed the same trends, but the levels were not so high. The different specimens do correlate well with each other (Table 9) In a former article we have described these data in detail [16].

\section{Further results}

Possible confounders were analyzed: age, gender, dental amalgam fillings, fish consumption and alcohol intake. Age was comparable in the subgroups. Gender analysis showed that the anamnestic symptoms were more prominent with

Table 8. Laboratory data of mercury-exposed gold miners

\begin{tabular}{|c|c|c|c|c|}
\hline \multirow{2}{*}{ Examined material } & \multicolumn{4}{|c|}{ Study group ${ }^{1}$} \\
\hline & non-exposed & low-exposed & medium-exposed & high-exposed \\
\hline \multicolumn{5}{|l|}{ Urine } \\
\hline respondents [n] & 208 & 406 & 181 & 452 \\
\hline \multicolumn{5}{|l|}{$\mathrm{Hg}[\mu \mathrm{g} / 1]$} \\
\hline $\mathrm{M} \pm \mathrm{SD}$ & $0.64 \pm 1.14$ & $7.95 \pm 44.7$ & $25.90 \pm 92.7$ & $69.40 \pm 288$ \\
\hline $\mathrm{Me}^{\# \# \#}$ & 0.10 & $2.30 * * *$ & $6.41 * * *$ & $12.0^{* * *}$ \\
\hline $\min .-\max$ & $<$ LOD-8.78 & $<$ LOD-874 & $<$ LOD-868 & $<$ LOD-5 240 \\
\hline $95 \%$ percentile & 3.16 & 22.1 & 70.8 & 274 \\
\hline respondents [n] & 156 & 398 & 179 & 447 \\
\hline \multicolumn{5}{|l|}{$\mathrm{Hg}[\mu \mathrm{g} / \mathrm{g}$ creatinine $]$} \\
\hline $\mathrm{M} \pm \mathrm{SD}$ & $0.77 \pm 1.45$ & $5.62 \pm 19.8$ & $18.80 \pm 51.3$ & $36.4 \pm 105$ \\
\hline $\mathrm{Me}^{\# \# \#}$ & 0.20 & $1.89^{* * *}$ & $4.36^{* * *}$ & $9.13^{* * *}$ \\
\hline $\min .-\max$ & $<$ LOD-9.31 & $<$ LOD-355 & $<$ LOD-409 & < LOD-1 697 \\
\hline $95 \%$ percentile & 3.57 & 18.9 & 79.6 & 143 \\
\hline \multicolumn{5}{|l|}{ Blood } \\
\hline respondents $[\mathrm{n}]$ & 165 & 353 & 168 & 438 \\
\hline \multicolumn{5}{|l|}{$\mathrm{Hg}[\mu \mathrm{g} / 1]$} \\
\hline $\mathrm{M} \pm \mathrm{SD}$ & $3.42 \pm 4.99$ & $6.47 \pm 12.3$ & $12.5 \pm 19.3$ & $17.3 \pm 37.3$ \\
\hline $\mathrm{Me}^{\# \# \#}$ & 0.94 & $3.64 * * *$ & $7.74^{* * *}$ & $7.56^{* * *}$ \\
\hline $\min .-\max$ & $<$ LOD-31.3 & $<$ LOD-172 & < LOD-145 & 429 \\
\hline $95 \%$ percentile & 14.3 & 19.8 & 42.6 & 56.4 \\
\hline
\end{tabular}


Table 8. Laboratory data of mercury-exposed gold miners - cont.

\begin{tabular}{|c|c|c|c|c|}
\hline \multirow{2}{*}{ Examined material } & \multicolumn{4}{|c|}{ Study group ${ }^{1}$} \\
\hline & non-exposed & low-exposed & medium-exposed & high-exposed \\
\hline \multicolumn{5}{|l|}{ Hair } \\
\hline respondents [n] & 189 & 399 & 177 & 411 \\
\hline \multicolumn{5}{|l|}{$\mathrm{Hg}$ total $[\mu \mathrm{g} / \mathrm{g}]$} \\
\hline $\mathrm{M} \pm \mathrm{SD}$ & $1.22 \pm 3.33$ & $2.72 \pm 7.01$ & $11.0 \pm 65.7$ & $8.49 \pm 23.3$ \\
\hline $\mathrm{Me}^{\# \# \#}$ & 0.21 & $1.23^{* * *}$ & $2.72 * * *$ & $2.40^{* * * *}$ \\
\hline $\min .-\max$ & $<$ LOD-34.7 & $<$ LOD-103 & $<$ LOD-792 & $<$ LOD-239 \\
\hline $95 \%$ percentile & 4.13 & 7.32 & 19.9 & 33.1 \\
\hline respondents $[\mathrm{n}]$ & 37 & 126 & 91 & 287 \\
\hline \multicolumn{5}{|l|}{$\mathrm{Hg}$ organic $[\mu \mathrm{g} / \mathrm{g}]$} \\
\hline $\mathrm{M} \pm \mathrm{SD}$ & $0.78 \pm 0.81$ & $2.05 \pm 5.29$ & $7.46 \pm 39.4$ & $2.83 \pm 6.53$ \\
\hline $\mathrm{Me}^{\# \# \#}$ & 0.27 & $0.99 * *$ & $1.26^{* * *}$ & $1.18^{* * *}$ \\
\hline $\min .-\max$ & $<$ LOD-3.35 & < LOD-51.1 & $<$ LOD-326 & $<$ LOD-83.3 \\
\hline $95 \%$ percentile & 2.11 & 5.55 & 5.86 & 10.5 \\
\hline respondents $[\mathrm{n}]$ & 37 & 126 & 91 & 287 \\
\hline \multicolumn{5}{|l|}{ Hg inorganic $[\mu \mathrm{g} / \mathrm{g}]$} \\
\hline $\mathrm{M} \pm \mathrm{SD}$ & $0.18 \pm 0.34$ & $2.69 \pm 7.10$ & $9.87 \pm 52.5$ & $8.07 \pm 23.2$ \\
\hline $\mathrm{Me}^{\# \# \#}$ & $<\mathrm{LOD}$ & $0.64 * * *$ & $0.91 * * *$ & $1.38^{* * * *}$ \\
\hline $\min .-\max$ & $<$ LOD-1.97 & $<$ LOD-52.1 & $<$ LOD-466 & $<$ LOD-225 \\
\hline $95 \%$ percentile & 0.77 & 13.8 & 13.4 & 32.1 \\
\hline
\end{tabular}

min. - minimal value; max - maximal value; LOD - limit of detection.

Other abbreviations as in Table 7.

${ }^{1}$ Study groups as in Table 5 .

Laboratory data Mann-Whitney test (exposed groups vs. control group): ${ }^{* *} \mathrm{p}<0.01 ;{ }^{* * *} \mathrm{p}<0.001$; Kruskal Wallis test: ${ }^{\# \#} \mathrm{p}<0.001$.

women, while clinical symptoms were to a lesser extent more common with men.

Twenty-four out of 1252 participants had dental amalgam fillings, 15 of them in the control group, 4 in the low-exposed group, 4 in the medium-exposed group and one in the high-exposed group.

In the Philippines and Indonesia, fish consumption is very common, whereas fish is less commonly consumed in Tanzania and Zimbabwe. In Mongolia, fish is rarely consumed. A correlation test showed that higher fish consumption was statistically significantly associated with higher mercury levels, especially in blood and hair (only organic mercury in hair) (Table 9). This correlation was also significant, but with a relatively low correlation coefficient of 0.319 , between fish consumption and medical score sum.

Alcohol ingestion can cause severe neurological symptoms. The separate analysis for female/male participants of the 4 subgroups did not show any significant difference between the men and women [45]. For this analysis, alcohol was not considered as a confounder. The main outcome is the prevalence rate of mercury intoxication in the different exposure groups. We used an algorithm to decide upon intoxication. The analysis showed significantly different prevalence rates for the 4 subgroups (Table 10). 


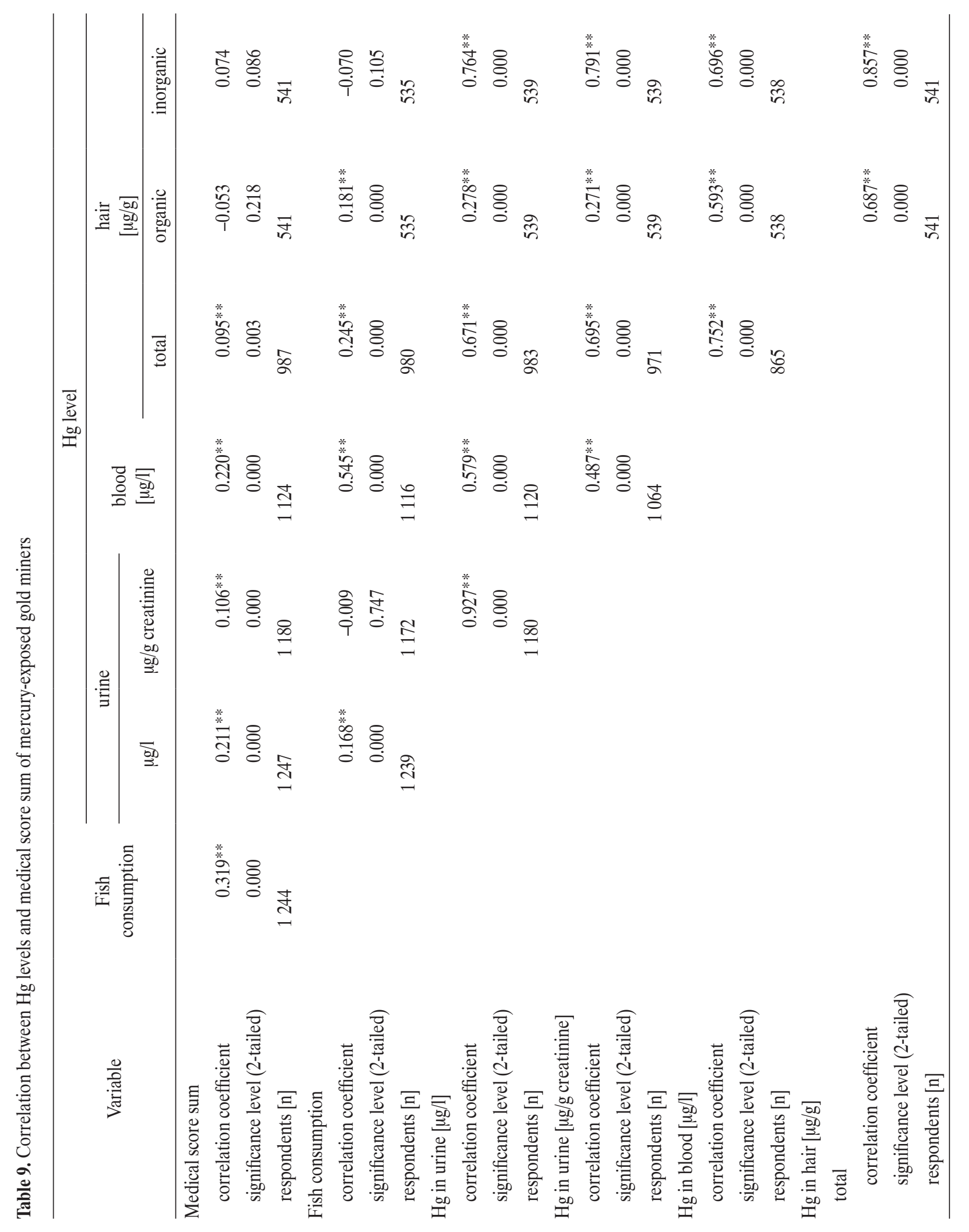



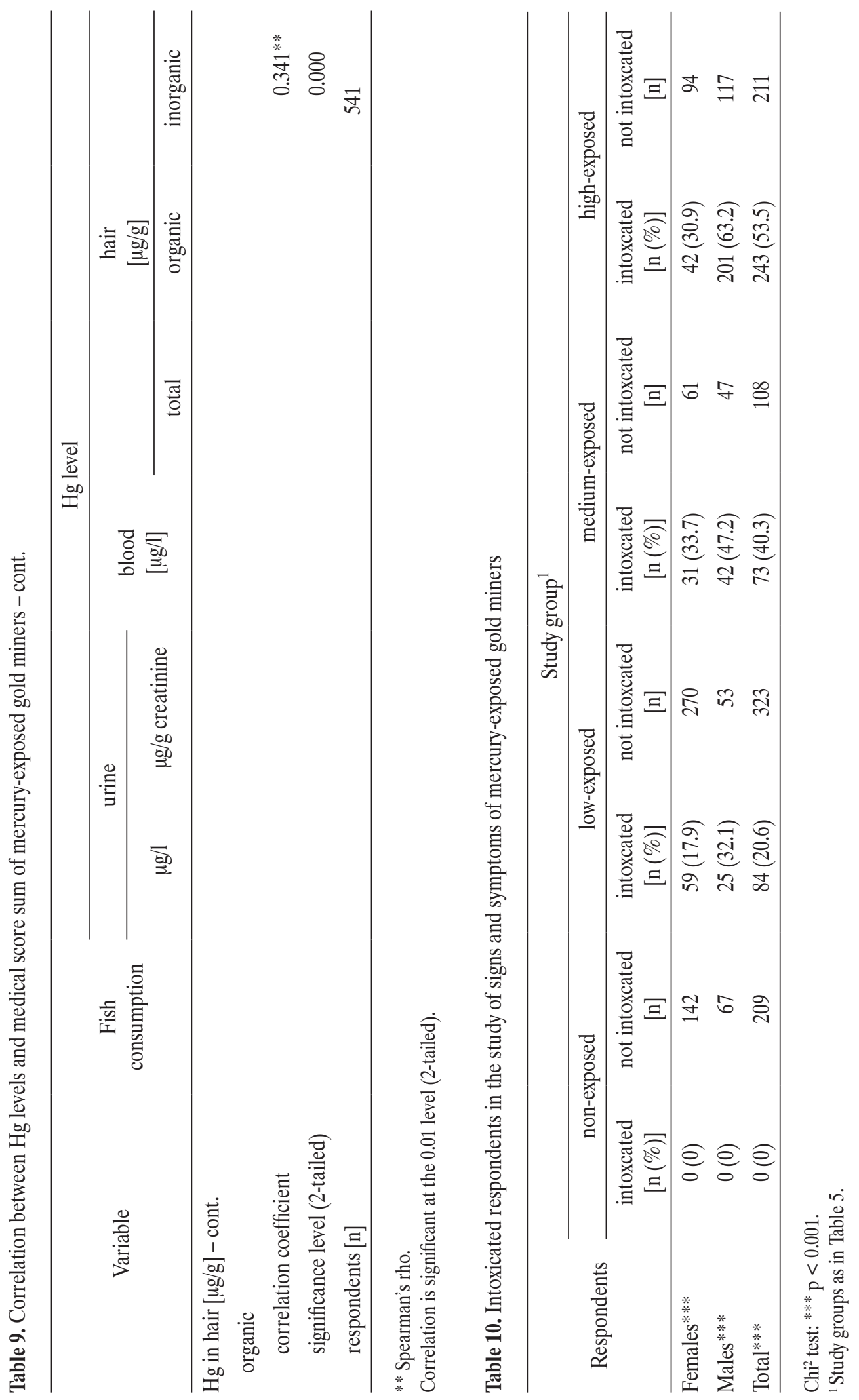
Highest rate was found in the high-exposure group (30.9\% of the female participants, $63.2 \%$ of the male participants). Second highest rate was found in the medium-exposed group (female 33.7\%, male 47.2\%). Lower rate was found in the low-exposed group (female 17.9\%, male $32.1 \%$ ). No participant from any control group was found to be intoxcated.

Men were more involved in the mining activities in our project sites. This difference might have been due to different exposure severity; men spend more time mining and are more likely to smelt the amalgams.

\section{DISCUSSION}

The results showed clearly that mercury exposure in ASGM areas leads to increased levels of mercury for the participants living in mining areas, and high to very high levels for participants working with mercury either as panners or amalgam burners. The participants developed typical neurological symptoms of chronic mercury intoxication depending on the severity of exposure.

\section{Confounders}

Age was not a significant confounder. Dental amalgam fillings were more common in the control groups. In control areas it is more likely to have a functioning health care service, whereas in ASGM areas health care hardly exists. This might explain the higher number of dental amalgam fillings in the control group. Dental amalgam fillings might contribute to the mercury body burden (increase the $\mathrm{Hg}$ level). Therefore, dental amalgam fillings cannot explain the higher mercury levels in exposed groups or the higher number of signs and symptoms. Dental amalgam fillings are therefore no confounding factor. Gender had an influence; women reported more frequently subjective symptoms compared to men, whereas objective symptoms were more likely with men. Perhaps women were more aware of their subjective wellbeing whereas men, due to the more severe mercury exposure, developed more symptoms.
Some of the results showed that the low-exposed group in particular exhibited more signs compared to the highexposed group. One of the possible explanations for this might have been the healthy worker effect. Higher fish consumption was correlated with higher mercury levels, especially in blood and hair. Alcohol consumption did not seem to be a confounder.

The respective project reports included statistical control of confounder and these confounders had no impact on key results presented in this paper. Furthermore a master thesis, explicitly focusing on different statistical methods to reanalyse the data, showed that confounders have no influence on the selection of the key signs and symptoms [45].

\section{Results}

As shown in Table 8, the mercury levels in urine, blood and hair were significantly different in the 4 exposure groups. The mercury levels were higher in Zimbabwe 2004, Indonesia and the Philippines, where mining activities were much stronger, compared to Tanzania, and mainly Mongolia and Zimbabwe 2006 with less intensive mining activities. The inorganic mercury vapor from mining was reflected in the very high levels of mercury in urine in the groups of high-exposed participants, the amalgam burners. Hair mercury levels reflect more methyl-mercury, for which the main pathway was fish consumption.

The correlation between the mercury levels in urine, blood and hair was statistically significant (Table 9). Blood results correlated closely with urine and all hair results. This was an indication that mercury in urine reflected more the acute exposure to elemental mercury. The main exposure was likely to be the elemental mercury vapor from burning amalgams, other important pathways were the environmental exposure in mining areas from panning with mercury, storing mercury in an insecure way at home and mercury releases from unprotected tailings. Organic mercury in hair reflected the additional exposure 
to methyl-mercury through fish consumption. Inorganic mercury in hair was related to the exposure from working with mercury. Total mercury in hair was an indicator for both, fish consumption and the long-term work exposure. To analyze this further, we took the different signs and symptoms and used the Mann-Whitney test to find out if the signs and symptoms were associated with the mercury levels (results not shown).

The symptom of metallic taste was statistically significantly associated with all specimen results, whereas symptoms such as excessive salivation, sleep disturbances and loss of hair were only associated with mercury levels in hair. The signs of ataxia of gait and heel to shin tremor were statistically significantly associated with all specimen results. The signs of grey to bluish discoloration of the oral cavity, finger to nose tremor, heel to shin ataxia, quadriceps reflex, mento-labial reflex were more likely to be related to mercury in hair or blood. Interestingly, many of these signs and symptoms were more closely associated with organic than inorganic mercury. May be this was an indication that inorganic mercury was transformed over the time into organic mercury. This hypothesis was supported by the fact that nearly all signs and symptoms were respectively associated with the total years of mercury exposure. This association between years of exposure and the different signs and symptoms was stronger compared to mercury levels in urine, blood and hair.

Neurological signs and symptoms developed slowly and depended on the dose as well as on the duration of exposure to mercury. Miners were not in a steady state of exposure. Therefore it was very likely that the association between long term and intensive exposure and chronic neurological signs and symptoms is causal. The medical score was statistically significantly associated with the total years of exposure (Mann-Whitney test $\mathrm{p}<0.001$ ) (boxplot - Figure 1). The health problems differed between the different mining areas. The percentage of intoxicated male miners was $89.5 \%$ for Zimbabwe 2004, 78.8\% for the

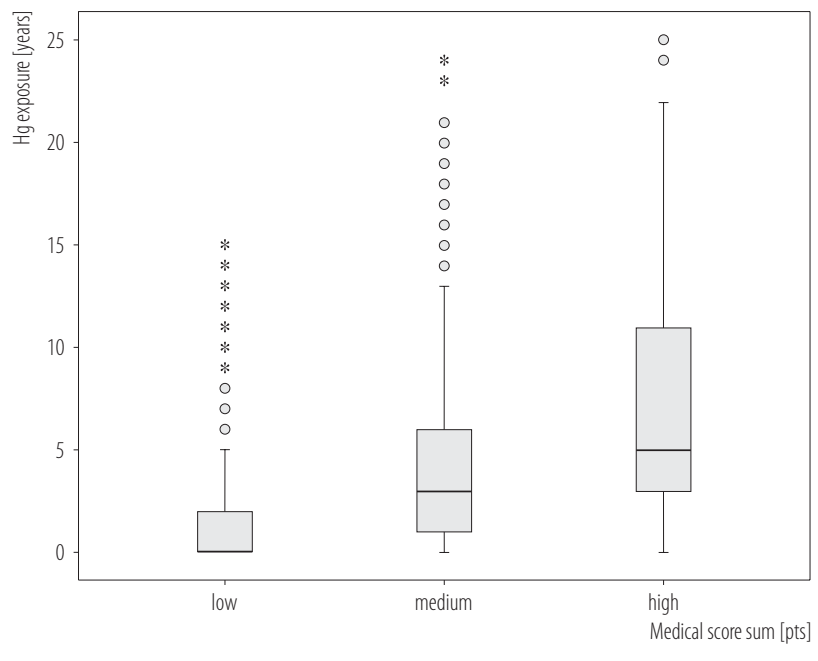

${ }^{*}$ Low $=0-4$, medium $=5-9$, high $=10-21$.

Fig. 1. Medical score sum* and total years of mercury exposure of gold miners

Philippines, 68.6\% for Indonesia-Kalimantan, and 23.5\% for Tanzania. This reflected the diverse extents of exposure of miners and community members due to different capacities to extract and mill ore, as well as the varying amounts of mercury used to process the ore.

In general, more men were intoxicated compared to women. The reason for this was that men were more likely to practice amalgam burning, whereas women were more likely to break the ores and perform the panning process. This unhealthy and dangerous mercury exposure in the immediate environment needs to be urgently reduced. There are technical alternatives to reduce the exposure [50]. Methods are also being developed to replace mercury in ASGM, e.g., with the so-called gravity-borax method [51,52].

The capabilities of health care systems in the sometimes remote areas are not sufficient to diagnose or treat chronic mercury intoxication. Laboratory capacities are only rarely available that can analyze mercury in urine alone. Health care providers have insufficient knowledge of the signs and symptoms of chronic mercury intoxication. Health care systems need to be prepared for this emerging 
problem of chronic mercury intoxication among exposed population in ASGM areas.

\section{Literature}

There are a number of publications available that address the issue of $\mathrm{Hg}$ as a health hazard in ASGM. Recently, a good review article was published [23]. This detailed article summarized the results from 26 studies, showing that the exposure to inorganic $\mathrm{Hg}$ vapor is high, and that toxic effects have to be considered. Some relevant papers in different countries with ASGM showed that $\mathrm{Hg}$ levels in any analyzed biomarker were higher compared to control groups or reference values, and in some studies clinical symptoms or negative results for subclinical parameters were identified [7,8,13,14,26,28,29,31,32,53-60]. These results are very similar to our results.

\section{Limitations}

This study was based on several different health assessments. All these studies used the same key questions in the questionnaire, same medical and neuro-psychological tests [61]. Not all health assessments had used all parameters. For example parameters that did not show any relevance were deleted in later-on studies, and additional new parameters tested. The risk groups differed, in general men, women and children were assessed (Philippines, Indonesia, Tanzania, Zimbabwe 2004); in Zimbabwe 2006 the risk group was mother-child pairs, and in Mongolia women at child bearing age (Table 1).

There might be biases, since the questionnaire surveys were performed by different nurses, the neuropsychological tests were done by different experts, but the examiner of the medical tests was always the same. Other bias might be due to imperfect information recall by exposed participants or controls. Miners did not work continuously with mercury; some workers might have been exposed nonstop, other just periodically. The main result of the reports from all surveyed countries was similar: high-exposed miners showed typical neurological signs and symptoms of chronic mercury intoxication.

Non-exposed participants were not selected at random; the selection was based on the experience of the national project manager to identify non-mercury-exposed participants with similar social and economic background.

Nevertheless, with 1252 participants, this is by far the largest cross-sectional cohort in ASGM areas. And this fairly big size of participant group facilitated the statistical analyses of data.

\section{CONCLUSIONS}

Chronic mercury intoxication, with tremor, ataxia and other neurological symptoms together with a raised body burden of mercury was clinically diagnosed in artisanal small-scale mining areas. Primary prevention is necessary, mercury exposure needs to be urgently reduced using available technical alternatives [50]. Health care systems need to be prepared for this emerging problem of chronic mercury intoxication among exposed people. It will be useful to develop a simplified screening tool to identify mercury-related health symptoms as early as possible.

\section{ACKNOWLEDGMENTS}

The different projects were only made possible by all the people who supported us so enormously. We want to thank Christian Beinhoff, Ludovic Bernaudat (UNIDO, Vienna, Austria), Saulo Rodriquez (CETEM, Rio de Janeiro, Brazil), Don Appleton (BGS, Nottingham, United Kingdom), Philippe Freysinnet and Pierre Billaud (BRGM, Orleans, France), Gustav Drasch, Beate Lettmeier, Stefan Maydl, Sven Illig, Katalin Drasch, Alexandra Dittmann (all LMU, Munich, Germany), Denis Shoko (UoZ, Harare, Zimbabwe), Mrs. Selinawati T. Darmutji (Indonesia), Aloyce Tesha (Tanzania), Kerstin Gutschmidt, Enkhtsetseg Shinee, Enkhjargal Altangerel, Burmaa Badrakh, Ichinkhorloo Bonduush, Unursaikhan Surenjav (WHO and MoH), Raffaella Matteucci Gothe, Jennifer Baeuml, Philip Ferstl (UMIT, Hall in Tirol, Austria). For their kind contributions we would like to 
thank Mineshi Sakamoto (National Institute of Minamata Disease, Minamata, Kumamoto, Japan), Jackie Morton, Kate Jones, Ovnair Sepai (Health and Safety Laboratory, Harpur Hill, Buxton, United Kingdom) and LMU. A very special thank you to all the doctors, nurses, experts and advisers in all field projects, and last but not least, to all participants who devoted their time to participate in the projects and entrusted us with their data.

\section{REFERENCES}

1. Drasch G, Horvat M, Stoeppler M. Mercury. In: Merian E, Anke M, Ihnat M, Stoeppler M, editors. Elements and their Compounds in the Environment. Weinheim: Wiley-VHC Verlag; 2004. p. 931-1005, https://doi.org/10.1002/9783527619 634.ch38.

2. Clarkson TW, Magos L. The toxicology of mercury and its chemical compounds. Crit Rev Toxicol. 2006;36(8):609-62, https://doi.org/10.1080/10408440600845619.

3. Spiegel SJ, Yassi A, Spiegel JM, Veiga MM. Reducing mercury and responding to the global gold rush. Lancet. 2005;366(9503):2070-2, https://doi.org/10.1016/S0140-6736(05) 67868-3.

4. United Nations Environment Programme. Chemicals Branch. The Global Mercury Assessment. Geneva: The Programme; 2013.

5. Schmidt CW. Quicksilver and gold: Mercury pollution from artisanal and small-scale gold mining. Environ Health Perspect. 2012;120(11):A424-9, https://doi.org/10.1289/ehp. 120-a424.

6. Akagi H, Castillo ES, Cortes-Maramba N, Francisco-Rivera AT, Timbang TD. Health assessment for mercury exposure among schoolchildren residing near a gold processing and refining plant in Apokon, Tagum, Davao del Norte, Philippines. Sci Total Environ. 2000;259(1-3):31-43, https://doi. org/10.1016/S0048-9697(00)00547-7.

7. Tomicic C, Vernez D, Belem T, Berode M. Human mercury exposure associated with small-scale gold mining in Burkina Faso. Int Arch Occup Environ Health. 2011;84(5):539-46, https://doi.org/10.1007/s00420-011-0615-x.
8. Cortes-Maramba N, Reyes JP, Francisco-Rivera AT, Akagi H, Sunio R, Panganiban LC. Health and environmental assessment of mercury exposure in a gold mining community in Western Mindanao, Philippines. J Environ Manage. 2006;81(2):126-34, https://doi.org/10.1016/j.jenvman. 2006.01.019.

9. Counter SA, Buchanan LH, Ortega F. Mercury levels in urine and hair of children in an Andean gold-mining settlement. Int J Occup Environ Health. 2005;11(2):132-7, https:// doi.org/10.1179/oeh.2005.11.2.132.

10. Counter SA, Buchanan LH, Ortega F. Neurocognitive screening of mercury-exposed children of Andean gold miners. Int J Occup Environ Health. 2006;12(3):209-14, https://doi.org/10.1179/oeh.2006.12.3.209.

11. Da Costa GM, dos Anjos LM, Souza GS, Gomes BD, Saito CA, Pinheiro Mda C, et al. Mercury toxicity in Amazon gold miners: Visual dysfunction assessed by retinal and cortical electrophysiology. Environ Res. 2008;107(1):98-107, https://doi.org/10.1016/j.envres.2007.08.004.

12. Harari R, Forastiere F, Axelson O. Unacceptable "occupational" exposure to toxic agents among children in Ecuador. Am J Ind Med. 1997;32(3):185-9, https://doi. org/10.1002/\%28SICI\%291097-0274\%28199709\%2932: 3\%3C185::AID-AJIM1\%3E3.0.CO;2-X.

13. Paruchuri Y, Siuniak A, Johnson N, Levin E, Mitchell K, Goodrich JM, et al. Occupational and environmental mercury exposure among small-scale gold miners in the TalensiNabdam District of Ghana's Upper East region. Sci Total Environ. 2010;408(24):6079-85, https://doi.org/10.1016/j.sci totenv.2010.08.022.

14. Van Straaten P. Human exposure to mercury due to small scale gold mining in northern Tanzania. Sci Total Environ. 2000;259(1-3):45-53, https://doi.org/10.1016/S00489697(00)00548-9.

15. Van Straaten P. Mercury contamination associated with small-scale gold mining in Tanzania and Zimbabwe. Sci Total Environ. 2000;259(1-3):105-13, https://doi.org/10.1016/ S0048-9697(00)00553-2. 
16. Baeuml J, Bose-O'Reilly S, Matteucci Gothe R, Lettmeier B, Roider G, Drasch G, et al. Human biomonitoring data from mercury exposed miners in six artisanal small-scale gold mining areas in Asia and Africa. Minerals. 2011;1(1):122-43, https://doi.org/10.3390/min1010122.

17. Bose-O'Reilly S, Drasch G, Beinhoff C, Rodrigues-Filho S, Roider G, Lettmeier B, et al. Health assessment of artisanal gold miners in Indonesia. Sci Total Environ. 2010;408(4): 713-25, https://doi.org/10.1016/j.scitotenv.2009.10.070.

18. Bose-O’Reilly S, Drasch G, Beinhoff C, Tesha A, Drasch K, Roider $\mathrm{G}$, et al. Health assessment of artisanal gold miners in Tanzania. Sci Total Environ. 2010;408(4):796-805, https:// doi.org/10.1016/j.scitotenv.2009.10.051.

19. Drasch G, Bose-O'Reilly S, Beinhoff C, Roider G, Maydl S. The Mt. Diwata study on the Philippines 1999 - assessing mercury intoxication of the population by small scale gold mining. Sci Total Environ. 2001;267:151-68, https:/doi. org/10.1016/S0048-9697(00)00806-8.

20. Steckling N, Boese-O'Reilly S, Gradel C, Gutschmidt K, Shinee E, Altangerel E, et al. Mercury exposure in female artisanal small-scale gold miners (ASGM) in Mongolia: An analysis of human biomonitoring (HBM) data from 2008. Sci Total Environ. 2011;409(5):994-1000, https://doi. org/10.1016/j.scitotenv.2010.11.029.

21. Olivero-Verbel J, Caballero-Gallardo K, Marrugo Negrete J. Relationship between localization of gold mining areas and hair mercury levels in people from Bolivar, north of Colombia. Biol Trace Elem Res. 2011;144(1-3):118-32, https:/doi. org/10.1007/s12011-011-9046-5.

22. Cordy P, Veiga MM, Salih I, Al-Saadi S, Console S, Garcia $\mathrm{O}$, et al. Mercury contamination from artisanal gold mining in Antioquia, Colombia: The world's highest per capita mercury pollution. Sci Total Environ. 2011;410-411:154-60, https://doi.org/10.1016/j.scitotenv.2011.09.006.

23. Kristensen AK, Thomsen JF, Mikkelsen S. A review of mercury exposure among artisanal small-scale gold miners in developing countries. Int Arch Occup Environ Health. 2013;87(6):579-90, https://doi.org/10.1007/s00420-013-0902-9.
24. Saunders JE, Jastrzembski BG, Buckey JC, Enriquez D, Mackenzie TA, Karagas MR. Hearing loss and heavy metal toxicity in a Nicaraguan mining community: Audiological results and case reports. Audiol Neurootol. 2013;18(2):101-13, https://doi.org/10.1159/000345470.

25. Engström K, Ameer S, Bernaudat L, Drasch G, Baeuml J, Skerfving S, et al. Polymorphisms in genes encoding potential mercury transporters and urine mercury concentrations in populations exposed to mercury vapor from gold mining. Environ Health Perspect. 2013;121(1):85-91, https://doi. org/10.1289/ehp.1204951.

26. Corral S, Sáez D, Lam G, Lillo P, Sandoval R, Lancellotti D, et al. Neurological and neuropsychological deterioration in artisanal gold miners from the town of Andacollo, Chile. Toxicol Environ Chem. 2013;95(2):344-58, https://doi.org/ 10.1080/02772248.2013.766191.

27. Yard EE, Horton J, Schier JG, Caldwell K, Sanchez C, Lewis $\mathrm{L}$, et al. Mercury exposure among artisanal gold miners in Madre de Dios, Peru: A cross-sectional study. J Med Toxicol. 2012;8(4):441-8, https://doi.org/10.1007/s13181-012-0252-0.

28. Ashe K. Elevated mercury concentrations in humans of Madre de Dios, Peru. PloS One. 2012;7(3):e33305, https:// doi.org/10.1371/journal.pone.0033305.

29. De Kom JF, van der Voet GB, de Wolff FA. Mercury exposure of maroon workers in the small scale gold mining in Suriname. Environ Res. 1998;77(2):91-7, https://doi. org/10.1006/enrs.1998.3835.

30. Gibb H, O'Leary KG. Mercury exposure and health impacts among individuals in the artisanal and small-scale gold mining community: A comprehensive review. Environ Health Perspect. 2014, https://doi.org/10.1289/ehp.1307864.

31. Corbett CE, El Khouri M, Costa AN, Gyuricza JV, Corbett JF, Frizzarini R, et al. Health evaluation of gold miners living in a mercury-contaminated village in Serra Pelada, Pará, Brazil. Arch Environ Occup Health. 2007;62(3):121-8, https://doi.org/10.3200/AEOH.62.3.121-128.

32. Harari R, Harari F, Gerhardsson L, Lundh T, Skerfving S, Stromberg U, et al. Exposure and toxic effects of elemental 
mercury in gold-mining activities in Ecuador. Toxicol Lett. 2012;213(1):75-82, https://doi.org/10.1016/j.toxlet.2011.09.006.

33. Suvd D, Davaadorj R, Baatartsol D, Unursaikhan S, Tsengelma M, Oyu T, et al. Toxicity assessment in artisanal miners from low-level mercury exposure in Bornuur and Jargalant soums of Mongolia. Procedia Environ Sci. 2015;30:97-102, https://doi.org/10.1016/j.proenv.2015.10.017.

34. Appleton JD, Taylor H, Lister TR, Smith B, Drasch G, Boese-O'Reilly S. Final report for an assessment of the environment and health in the Rwamagasa area, Tanzania. UNIDO Project EG/GLO/01/G34 [Internet]. Keyworth, Nottingham: British Geological Survey; 2004 [cited 2015 May 22]. Available from:http:/www.unites.uqam.ca/gmf/intranet/gmp/ countries/tanzania/doc/CR04129\%20v3_.pdf.

35. Lettmeier B, Boese-O'Reilly S, Drasch G. Proposal for a revised Reference Concentration (RfC) for mercury vapour in adults. Sci Total Environ. 2010;408:3530-5, https://doi. org/10.1016/j.scitotenv.2010.04.027.

36. Rodrigues-Filho S, Luiz Correa dos Santos R, Villas Bôas RC, Carmen Castilhos Z, Yallouz AV, Peregovich B, et al. Environmental and health assessment in 2 small-scale gold mining areas - Indonesia final report - Sualwesi and Kalimantan. UNIDO - EG/GLO/01/G34 - Removal of barriers to the introduction of cleaner artisanal gold mining and extraction technologies. Rio de Janeiro: Centre For Mineral Technology; 2004.

37. Steckling N, Bose-O'Reilly S, Pinheiro P, Plass D, Shoko D, Drasch G, et al. The burden of chronic mercury intoxication in artisanal small-scale gold mining in Zimbabwe: Data availability and preliminary estimates. Environ Health. 2014;13(1):111, https://doi.org/10.1186/1476-069X-13-111.

38. Bose-O'Reilly S, Lettmeier B, Gothe RM, Beinhoff C, Siebert U, Drasch G. Mercury as a serious health hazard for children in gold mining areas. Environ Res. 2008;107(1): 89-97, https://doi.org/10.1016/j.envres.2008.01.009.

39. Masur H, Papke K, Althoff S, Oberwittler C, Heil U, Hundenborn S, et al., editors. [Scales and Scores in Neurology]. 2nd ed. Stuttgart: Georg Thieme Verlag; 2000. German.
40. Wessely S, Powell R. [Fatigue syndrome]. In: Masur H, Papke K, Althoff S, Oberwittler C, Heil U, Hundenborn S, et al., editors. [Scales and Scores in Neurology]. 2nd ed. Stuttgart: Georg Thieme Verlag; 2000. German.

41. Lockowandt O. [Frostigs developmental tests of visual perception]. Weinheim: Beltz; 1996. German.

42. Zimmer R, Volkamer M. [Motor function test for children aged 4 to 6]. 2nd ed. Weinheim: Beltz Test Gesellschaft; 1987. German.

43. Mazzachi BC, Peake MJ, Ehrhardt V. Reference range and method comparison studies for enzymatic and Jaffe creatinine assays in plasma and serum and early morning urine. Clin Lab. 2000;46:53-5.

44. Bose-O'Reilly S, Dahlmann F, Lettmeier B, Drasch G. Removal of barriers to the introduction of cleaner artisanal gold mining and extraction technologies in Kadoma, Zimbabwe Final report, part B Health assessment. UNIDO Project EG/GLO/01/G34 No.03/089. BRGM Project Nr 822657-3. Orleans, France: Bureau de Recherches Géologiques et Minières; 2004.

45. Doering S. Essential indicators identifying chronic inorganic mercury intoxication. Munich: Ludwig-Maximilians-Universität München; 2014.

46. Schulz C, Angerer J, Ewers U, Kolossa-Gehring M. The German Human Biomonitoring Commission. Int J Hyg Environ Health.2007;210(3-4):373-82,https://doi.org/10.1016/j.ijheh. 2007.01.035.

47. Wilhelm M, Ewers U, Schulz C. Revised and new reference values for some trace elements in blood and urine for human biomonitoring in environmental medicine. Int J Hyg Environ Health. 2004;207(1):69-73, https://doi.org/10.1078/14384639-00260.

48. Drasch G, Bose-O’Reilly S, Maydl S, Roider G. Scientific comment on the German human biological monitoring values (HBM values) for mercury. Int J Hyg Environ Health. 2002;205(6):509-12, https://doi.org/10.1078/1438-4639-00178. 49. Schulz C, Wilhelm M, Heudorf U, Kolossa-Gehring M. Update of the reference and HBM values derived by the 
German Human Biomonitoring Commission. Int J Hyg Environ Health. 2011;215(1):26-35, https://doi.org/10.1016/j.ij heh.2011.06.007.

50. Telmer K, Stapper D. A practical guide: Reducing mercury use in artisanal and small-scale gold mining. Geneva: United Nations Environment Programme; 2012.

51. Appel PWU, Na-Oy L. The borax method of gold extraction for small-scale miners. J Health Pollut. 2012;2(3):5-10, https://doi.org/10.5696/2156-9614-2.3.5.

52. Steckling N, Böse-O'Reilly S, Shoko D, Muschack S, Schierl R. Testing local conditions for the introduction of a mercury-free gold extraction method using borax in Zimbabwe. J Health Pollut. 2014;7:54-61, https://doi.org/10.5696/21569614-4-7.54.

53. Malm O, Branches FJ, Akagi H, Castro MB, Pfeiffer WC, Harada M, et al. Mercury and methylmercury in fish and human hair from the Tapajós river basin, Brazil. Sci Total Environ. 1995;175(2):141-50, https://doi.org/10.1016/00489697(95)04910-X.

54. Santos EC, de Jesus IM, Camara Vde M, Brabo E, Loureiro EC, Mascarenhas A, et al. Mercury exposure in Munduruku Indians from the community of Sai Cinza, State of Pará, Brazil. Environ Res. 2002;90(2):98-103, https://doi.org/10.1006/ enrs.2002.4389.

55. Castilhos ZC, Rodrigues-Filho S, Rodrigues AP, VillasBoas RC, Siegel S, Veiga MM, et al. Mercury contamination in fish from gold mining areas in Indonesia and human health risk assessment. Sci Total Environ. 2006;368(1): 320-5, https://doi.org/10.1016/j.scitotenv.2006.01.039.

56. Hurtado J, Gonzales GF, Steenland K. Mercury exposures in informal gold miners and relatives in southern Peru. Int J Occup Environ Health. 2006;12(4):340-5, https://doi. org/10.1179/oeh.2006.12.4.340.

57. Peplow D, Augustine S. Community-directed risk assessment of mercury exposure from gold mining in Suriname. Rev Panam Salud Publica. 2007;22(3):202-10, https://doi. org/10.1590/S1020-49892007000800007.

58. Tian L, Guo HF, Gao A, Lu XT, Li QY. Effects of mercury released from gold extraction by amalgamation on renal function and environment in Shanxi, China. Bull Environ Contam Toxicol. 2009;83(1):71-4, https://doi.org/10.1007/ s00128-009-9722-8.

59. Barbieri FL, Cournil A, Gardon J. Mercury exposure in a high fish eating Bolivian Amazonian population with intense small-scale gold-mining activities. Int J Environ Health Res. 2009;19(4):267-77, https://doi.org/ 10.1080/09603120802559342.

60. Oosthuizen MA, John J, Somerset V. Mercury exposure in a low-income community in South Africa. S Afr Med J. 2010;100(6):366-71, https://doi.org/10.7196/samj.3863.

61. Veiga MM, Baker RF. Protocols for environmental and health assessment of mercury released by artisanal and small-scale miners. Global Mercury Project. Vienna: UNIDO Vienna International Center; 2004.

This work is available in Open Access model and licensed under a Creative Commons Attribution-NonCommercial 3.0 Poland License - http://creativecommons.org/ licenses/by-nc/3.0/pl/deed.en. 